\title{
Reappraisal of bicarbonate secretion by the human oesophagus
}

\author{
A Mertz-Nielsen, J Hillingsø, K Bukhave, J Rask-Madsen
}

\begin{abstract}
Background and aims-Administration of omeprazole to healthy volunteers was recently reported to increase proximal duodenal mucosal bicarbonate secretion. As human oesophagus also secretes bicarbonate, the hypothesis was tested that omeprazole may stimulate oesophageal bicarbonate secretion and thus contribute to the therapeutic efficacy of the drug in gastro-oesophageal reflux disease.

Subjects and methods-In nine healthy volunteers, oesophageal "steady state" perfusion of a $10 \mathrm{~cm}$ open segment of distal oesophagus was performed twice in random order. The volunteers were pretreated with either $60 \mathrm{mg} / \mathrm{day}$ omeprazole for three days and $80 \mathrm{mg}$ intravenous omeprazole before perfusion or $600 \mathrm{mg} /$ day ranitidine for three days and $50 \mathrm{mg} / \mathrm{h}$ intravenously during the perfusion. Saliva and samples of aspirate from the perfused oesophagus and stomach were collected and bicarbonate concentrations were measured.
\end{abstract}

Results-The median rates (95\% confidence intervals) of intrinsic oesophageal bicarbonate secretion, corrected for contaminating salivary and gastric bicarbonate, were $89(33-150)$ and 121 (68-203) $\mu \mathrm{mol} / \mathrm{h} / 10 \mathrm{~cm}(p>0.5)$ in omeprazole and ranitidine treated subjects respectively. Salivary and gastric bicarbonate contaminating the oesophagus accounted for $14 \%$ and $3 \%$, respectively, of total oesophageal bicarbonate output.

Conclusions-Bicarbonate secretory capacity of the human oesophagus is less than previously assumed, and the clinical relevance of intrinsic oesophageal bicarbonate for mucosal defence may be overestimated. As omeprazole and ranitidine did not affect bicarbonate secretion differently there was no evidence that omeprazole acts on bicarbonate secretory cells in the oesophageal mucosa.

(Gut 1997; 40: 582-586)

Keywords: bicarbonate secretion, oesophagus, omeprazole, ranitidine.

Bicarbonate secretion by the human oesophagus - supposed to originate in submucosal glands - has recently been implicated as a protective mechanism against damage from refluxed gastric acid. ${ }^{12}$ However, reported secretory rates varied from 156 to $489 \mu \mathrm{mol} /$ $\mathrm{h} / 10 \mathrm{~cm}$, which clouds the interpretation that intrinsic oesophageal bicarbonate secretion is important for clearance of refluxed gastric acid compared with the salivary component of acid neutralisation. The findings of an incremental increase in oesophageal $\mathrm{pH}$ with repeat swallows ${ }^{3}{ }^{4}$ and stimulation of salivary bicarbonate secretion by oesophageal acidification, suggesting the existence of an oesophagosalivary reflex, ${ }^{25}$ have previously established the importance of salivary bicarbonate. On the other hand, in vitro experiments suggest that intrinsic oesophageal bicarbonate secretion rates of about $160 \mu \mathrm{mol} / \mathrm{h}$ are capable of neutralising $1 \mathrm{ml}$ of acid with a $\mathrm{pH}>2 \cdot 0,{ }^{1}$ which seems representative of the residual volume present within the oesophageal lumen after an episode of reflux and bolus clearance by peristalsis. ${ }^{3}{ }^{4}$

The proton pump inhibitor omeprazole has recently been shown to enhance duodenal mucosal bicarbonate secretion in healthy volunteers independent of its gastric acid inhibitory effect. ${ }^{6}$ This increase in duodenal neutralising capacity is likely to add to the well documented superiority of omeprazole in duodenal ulcer healing over histamine $\mathrm{H}_{2}$ receptor antagonists. In the treatment of gastro-oesophageal reflux disease omeprazole is again superior to histamine $\mathrm{H}_{2}$ receptor antagonists. ${ }^{7} 8$ It remains to be established whether omeprazole has a stimulatory effect of its own on oesophageal bicarbonate secretion, which might contribute to the therapeutic gain. We have, therefore, made an attempt to measure human oesophageal bicarbonate secretion more accurately to allow assessment of the in vivo effect of omeprazole on intrinsic oesophageal bicarbonate secretion in healthy volunteers.

\section{Methods}

SUBJECTS

Ten healthy volunteers (six men and four women, median age 26 , range $20-42$ years), with no past or current gastrointestinal or other medical diseases, were studied by a protocol approved by the Copenhagen and Frederiksberg ethics committee. Each participant gave written informed consent.

\section{EXPERIMENTAL DESIGN}

Nine of the subjects were studied twice after an overnight fast. Before perfusion the subjects were randomly pretreated with either omeprazole $(60 \mathrm{mg} /$ day for three days and $80 \mathrm{mg}$ 
intravenously one hour before perfusion) or ranitidine $(600 \mathrm{mg} /$ day for three days and 50 $\mathrm{mg} / \mathrm{h}$ intravenously during perfusion). Firstly, a double lumen gastric tube (16 French, AN 10 Anderson Samplers Inc, Atlanta, GA, USA) was introduced nasally and placed in the distal antrum. The infusion port was located $8 \mathrm{~cm}$ proximal to the aspiration port. Secondly, a similar double lumen tube was introduced orally and placed in the distal oesophagus. The infusion port was located $10 \mathrm{~cm}$ orally to the aspiration ports, which were positioned $35 \mathrm{~cm}$ from the incisors (Figure). Experiments were performed with subjects in a semireclined position. The oesophagus was perfused (Ivac 560 Pump, NC Nielsen, Glostrup, Denmark) with isotonic saline $(5 \mathrm{ml} / \mathrm{min} ; \mathrm{pH} 7 \cdot 0)$ using $\left[{ }^{51} \mathrm{Cr}\right]$ EDTA $(10 \mu \mathrm{Ci} / \mathrm{l})$ as a non-absorbable marker. The stomach was similarly perfused with isotonic saline containing phenol red (50 $\mathrm{mg} / \mathrm{l} ; \mathrm{pH} 7 \cdot 0$ ), at a constant rate of $2 \mathrm{ml} / \mathrm{min}$ (LKB 2115 Multiperpex Pump, Bromma, Sweden). During experiments, the subjects were instructed to avoid swallowing saliva, which was removed by buccal aspiration. After an initial 30 minute equilibration period all effluents were collected at 15 minute intervals for one hour (from the mouth, oesophagus, and stomach) by intermittent suction (Pump AB, Einar Egnell, Trollhättan, Sweden) for analysis.

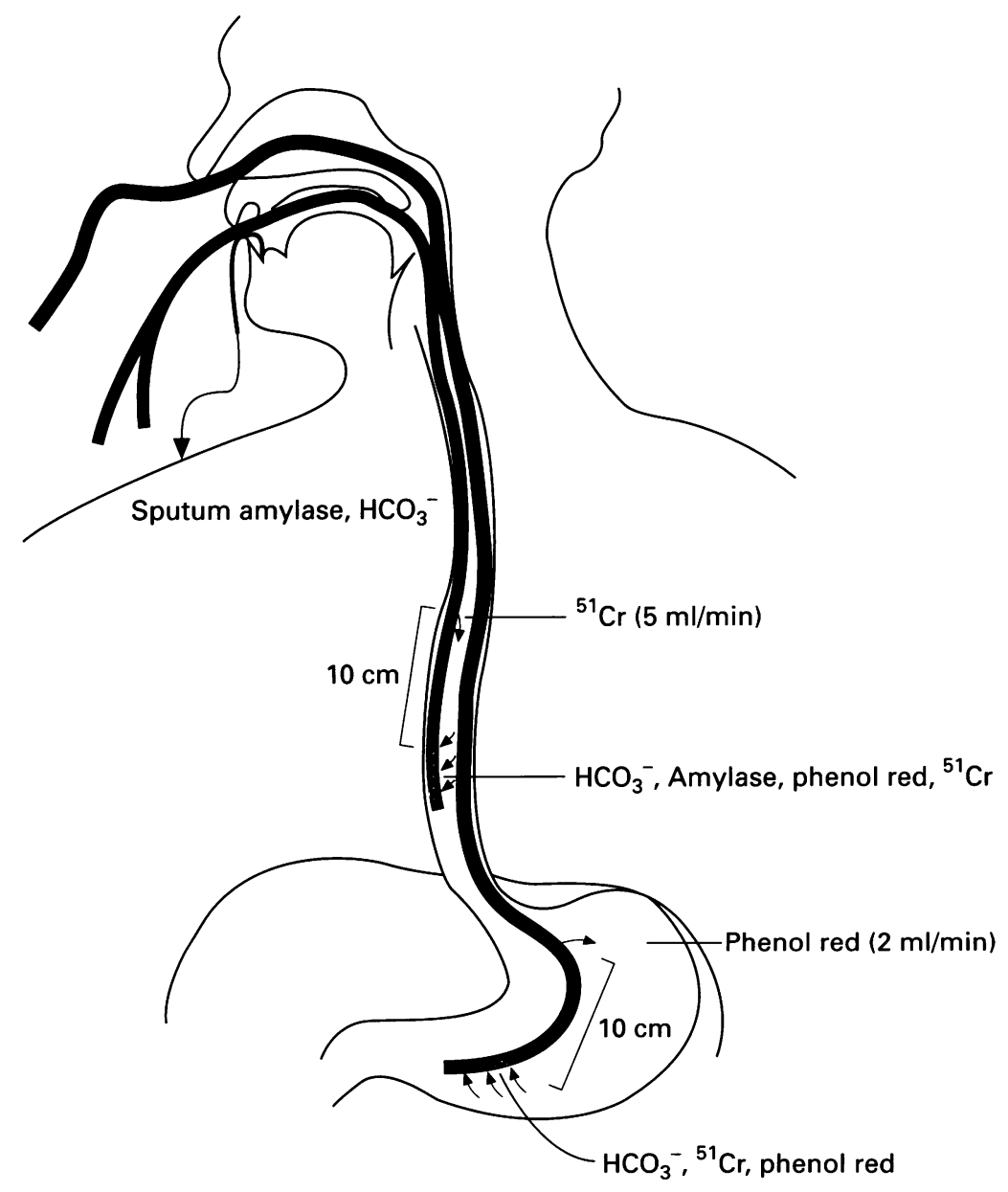

Diagram of tube position for measuring intrinsic oesophageal bicarbonate secretion and contamination by swallowed salivary and refluxed gastric bicarbonate in the human oesophagus.
ANALYTICAL PROCEDURES

The $\mathrm{pH}$ values of the aspirates were immediately measured by a glass electrode attached to a standard pH meter (PHM82, Radiometer, Copenhagen, Denmark), which was calibrated daily by standard buffer solu-

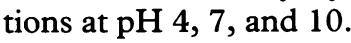

Concentrations of bicarbonate in $100 \mu$ l aliquots of saliva and aspirates from the oesophagus and the stomach were determined in triplicate (Corning 965 Carbon Dioxide Analyzer, Corning Ltd., Halstead, UK). This method corresponds to the back titration method, ${ }^{9}$ which has previously been shown to determine oesophageal bicarbonate secretion more accurately than the $\mathrm{pH} / \mathrm{pCO}_{2}$ method. ${ }^{2}$ Before analysis the samples were gassed with $\mathrm{CO}_{2}$ free nitrogen for five minutes to remove dissolved carbon dioxide. The Corning analyser was calibrated daily against 1.0 and $2.5 \mathrm{mM} \mathrm{NaHCO}_{3}$. The between day variability, expressed as coefficient of variation, was $12 \%(n=20)$ and $6 \%(n=20)$ respectively.

To determine the contamination of the oesophageal test segment with saliva, amylase concentrations were measured in samples of saliva and aspirates from the oesophagus by an enzymatic, colorimetric method using maltoheptaoside (Merck, Darmstadt, Germany) as a substrate.

Activities of $\left[{ }^{51} \mathrm{Cr}\right]$ and concentrations of phenol red were determined both in oesophageal and gastric aspirates and served as markers for recovery and contamination of the respective test segment. Activities of $\left[{ }^{51} \mathrm{Cr}\right]$ were measured by gamma spectrometry. Concentrations of phenol red were measured spectrophotometrically at $560 \mathrm{~nm}$ after being made alkaline $(\mathrm{pH}=11)$ by a $4+1$ dilution with a $0.5 \mathrm{M} \mathrm{Na}_{2} \mathrm{PO}_{4}$ solution.

\section{VALIDATION STUDIES}

In vitro bicarbonate studies

The accuracy of the Corning 965 carbon dioxide analyser for determination of bicarbonate concentrations was tested by performing 10 measurements on each of $0 \cdot 5,1 \cdot 0,2 \cdot 5,5 \cdot 0$, and $10.0 \mathrm{mM}$ standard bicarbonate solutions. These results were compared with those obtained by using the original back titration method.

In vivo infusion of bicarbonate

In three of the subjects additional experiments were performed to determine the accuracy of the perfusion method for measurement of oesophageal bicarbonate secretion. After a 30 minute equilibration period, basal bicarbonate secretion was determined for 30 minutes as described above. During the next four 30 minute periods a $5 \mathrm{ml}$ bolus containing 100 , 250,500 , or $1000 \mu \mathrm{mol}$ sodium bicarbonate was infused and total bicarbonate output was calculated. Subsequently, the amount of infused bicarbonate was calculated by subtracting basal bicarbonate secretion from total bicarbonate output during the periods of exogenous bicarbonate infusion. 
CALCULATIONS AND STATISTICAL ANALYSES Previously described formulas for a "steady state" perfusion system were used for calculation of oesophageal fluid output and bicarbonate secretion, in addition to contamination of the oesophageal test segment with salivary and gastric bicarbonate. ${ }^{210}$ Rates of intrinsic oesophageal bicarbonate secretion were calculated by subtracting contaminating saliva and gastric bicarbonate from the total amount of bicarbonate in the oesophageal perfusate in individual 15 minute periods and given as means of the four 15 minute values obtained in each experiment.

The results were expressed as median values with $95 \%$ confidence intervals (95\% CI). The Wilcoxon signed rank test and the Spearman rank order correlation test were used for statistical analyses. ${ }^{11}$ All $p$ values calculated were two tailed and the $\alpha$ level of significance was set at $0 \cdot 05$.

\section{Results}

\section{VALIDATION OF METHOD}

In vitro bicarbonate studies

Analysis of standard bicarbonate solutions $(0.5,1 \cdot 0,2 \cdot 5,5 \cdot 0,10.0 \mathrm{mM})$ by the Corning analyser showed a highly significant correlation $(r=0.99 ; \mathrm{p}<0.001)$ between measured and known concentrations. Also the results obtained by back titration showed a high degree of correlation with those obtained by the Corning analyser $(r=0.99 ; \mathrm{p}<0.001)$.

\section{In vivo infusion of bicarbonate}

The amounts of bicarbonate infused into the oesophagus were linearly correlated with the bicarbonate output adjusted for intrinsic oesophageal bicarbonate secretion $(r=0.96$; $\mathrm{p}<0.005)$. Also, the amounts of bicarbonate infused into the oesophagus during the first two 30 minute periods (100 and $250 \mu \mathrm{mol}$ sodium bicarbonate) corresponded with those secreted by the oesophageal segment.

\section{Measurement of $p H$ and marker recovery}

There were no significant differences between omeprazole and ranitidine treated subjects in median values of oesophageal and gastric $\mathrm{pH}$ measurements, salivary and oesophageal amylase concentrations, or oesophageal and gastric recoveries of $\left[{ }^{51} \mathrm{Cr}\right]$ and phenol red (Table I).

\section{BASAL BICARBONATE SECRETION}

The median rates of intrinsic oesophageal bicarbonate secretion, corrected for contaminating salivary and gastric bicarbonate, were $89(33-150)$ and $121(68-203) \mu \mathrm{mol} / \mathrm{h} / 10 \mathrm{~cm}$ after pretreatment with omeprazole and ranitidine respectively $(p>0 \cdot 5)$.

The outputs of bicarbonate in saliva after omeprazole and ranitidine pretreatment were 493 (116-3552) and 1532 (1016-3967) $\mu \mathrm{mol} / \mathrm{h}$ respectively $(\mathrm{p}<0 \cdot 05)$. All oesophageal aspirates contained varying low concentrations of amylase, indicative of swallowed saliva. The median contents of salivary bicarbonate contaminating the oesophageal test segment were $22(1-50) \mu \mathrm{mol} / \mathrm{h}$ in omeprazole experiments and $16(13-26) \mu \mathrm{mol} / \mathrm{h}$ in ranitidine experiments ( $>0.5)$, thus accounting for about $18 \%$ and $10 \%$, respectively, of total oesophageal bicarbonate output.

The outputs of bicarbonate into the stomach after omeprazole and ranitidine pretreatment were 344 (259-828) and 307 (286-513) $\mu \mathrm{mol} / \mathrm{h}$ $(p>0.5)$ respectively. Reflux of gastric bicarbonate was not found in all oesophageal samples. The median contents of gastric bicarbonate refluxed into the oesophageal test segment were $3(0-4) \mu \mathrm{mol} / \mathrm{h}$ in omeprazole experiments and $4(2-80) \mu \mathrm{mol} / \mathrm{h}$ in ranitidine experiments $(p<0.02)$, thus accounting for about $3 \%$ of total oesophageal bicarbonate output.

Table II presents the data obtained in individual subjects.

TABLE I pH measurements and recoveries of phenol red and $\left.{ }^{51} \mathrm{Cr}\right]$ in oesophagus and stomach, and amylase concentrations in saliva and oesophagus after pretreatment with omeprazole (OME) and ranitidine (RAN) (medians and $95 \% C I ; n=9)$

\begin{tabular}{|c|c|c|c|c|c|c|c|c|}
\hline & \multicolumn{2}{|l|}{$p H$} & \multicolumn{2}{|l|}{$\left[{ }^{5 l} \mathrm{Cr}\right](\%)$} & \multicolumn{2}{|c|}{ Phenol red (\%) } & \multicolumn{2}{|l|}{ Amylase (kU/) } \\
\hline & Oesophagus & Stomach & Oesophagus & Stomach & Oesophagus & Stomach & Saliva & Oesophagus \\
\hline $\begin{array}{l}\text { OME } \\
\text { RAN }\end{array}$ & $\begin{array}{l}6 \cdot 8(6 \cdot 6-6 \cdot 9) \\
6 \cdot 7(6 \cdot 6-6 \cdot 8)\end{array}$ & $\begin{array}{l}6 \cdot 8(6 \cdot 7-7 \cdot 0) \\
6.9(6 \cdot 7-7 \cdot 0)\end{array}$ & $\begin{array}{l}93(93-99) \\
91(79-97)\end{array}$ & $\begin{array}{l}19(6-31) \\
19(5-28)\end{array}$ & $\begin{array}{l}0.3(0-0.6) \\
0.6(0-7.3)\end{array}$ & $\begin{array}{l}73(57-83) \\
69(56-83)\end{array}$ & $\begin{array}{l}108(82-256) \\
132(94-245)\end{array}$ & $\begin{array}{l}0.4(0.3-2.8) \\
0.5(0.2-2 \cdot 4)\end{array}$ \\
\hline
\end{tabular}

TABLE II Individual data in nine subjects indicating intrinsic oesophageal bicarbonate output and contamination by salivary bicarbonate and refluxed gastric bicarbonate after pretreatment with omeprazole and ranitidine

\begin{tabular}{|c|c|c|c|c|c|c|}
\hline \multirow[b]{2}{*}{ No } & \multicolumn{3}{|l|}{ Omeprazole } & \multicolumn{3}{|l|}{ Ranitidine } \\
\hline & $\begin{array}{l}\text { Net oesophageal } \\
\mathrm{HCO}_{3}^{-} \text {output } \\
(\mu \mathrm{mol} / \mathrm{h} / 10 \mathrm{~cm})\end{array}$ & $\begin{array}{l}\text { Salivary } \mathrm{HCO}_{3}^{-} \\
\text {contamination } \\
(\mu \mathrm{mol} / \mathrm{h})\end{array}$ & $\begin{array}{l}\text { Gastric } \mathrm{HCO}_{3}^{-} \\
\text {contamination } \\
(\mu \mathrm{mol} / \mathrm{h})\end{array}$ & $\begin{array}{l}\text { Net oesophageal } \\
\mathrm{HCO} \mathrm{O}_{3}^{-} \text {output } \\
(\mu \mathrm{mol} / \mathrm{h} / 10 \mathrm{~cm})\end{array}$ & $\begin{array}{l}\text { Salivary } \mathrm{HCO}_{3}^{-} \\
\text {contamination } \\
(\mu \mathrm{mol} / \mathrm{h})\end{array}$ & $\begin{array}{l}\text { Gastric } \mathrm{HCO}_{3}^{-} \\
\text {contamination } \\
(\mu \mathrm{mol} / \mathrm{h})\end{array}$ \\
\hline $\begin{array}{l}1 \\
2 \\
3 \\
4 \\
5 \\
6 \\
7 \\
8 \\
8 \\
9\end{array}$ & $\begin{array}{r}77 \\
135 \\
79 \\
25 \\
150 \\
150 \\
122 \\
33 \\
89\end{array}$ & $\begin{array}{r}1 \\
10 \\
46 \\
1 \\
22 \\
164 \\
50 \\
25 \\
6\end{array}$ & $\begin{array}{r}1 \\
4 \\
0 \\
0 \\
12 \\
3 \\
1 \\
3 \\
3\end{array}$ & $\begin{array}{r}38 \\
68 \\
127 \\
88 \\
91 \\
121 \\
129 \\
284 \\
203\end{array}$ & $\begin{array}{r}16 \\
14 \\
21 \\
8 \\
13 \\
23 \\
26 \\
16 \\
89\end{array}$ & $\begin{array}{r}0 \\
80 \\
4 \\
2 \\
351 \\
11 \\
4 \\
4 \\
8\end{array}$ \\
\hline
\end{tabular}




\section{Discussion}

The results of this study support recent findings suggesting that human oesophagus has the ability to secrete bicarbonate into the lumen. ${ }^{2}$ The origin of bicarbonate has been attributed to submucosal glands present in human oesophagus. ${ }^{12}$ Rabbit oesophagus, which is devoid of submucosal glands, does not seem to secrete bicarbonate, ${ }^{13}$ which emphasises the role of these glands in bicarbonate secretion by the oesophagus.

The functional relevance of intrinsic oesophageal bicarbonate secretion and other protective mechanisms, such as salivary bicarbonate and mucous secretion and oesophageal mucous secretion, motor activity, mucosal blood flow, and epithelial cell proliferation and resistance, is to maintain mucosal integrity after exposure to aggressive factors, such as acid and pepsin. ${ }^{14}$ The importance of the low rates of oesophageal bicarbonate secretion for neutralisation of gastric acid seems, however, overestimated in the light of the part played by salivary bicarbonate and peristaltic movements. In the present study, the rates of bicarbonate secretion into saliva were about 10 -fold higher than the output of intrinsic oesophageal bicarbonate. Similarly, other studies have clearly shown the importance of saliva for acid clearance in the oesophagus ${ }^{34}$ and the capability of oesophageal peristalsis to reduce the bolus from a reflux period to less than $1 \mu \mathrm{l}$. Nevertheless, the median rates of oesophageal bicarbonate secretion found would still be sufficient to neutralise a volume $<1 \mathrm{ml}$ with a $\mathrm{pH}>2 \cdot 5,{ }^{2}$ which is consistent with the previously noted non-salivary component of luminal acid clearance. ${ }^{3415}$ Furthermore, the oesophagus seems to have additional capacity for luminal acid clearance, as it has been shown that topical acidification stimulates bicarbonate secretion. ${ }^{16}$

Isolation of intestinal segments by occluding balloons for prevention of contaminating fluids from adjacent segments provides an attractive model for the in vivo study of ionic transport in the gastrointestinal tract. This approach has proved useful in the human duodenum and jejunum, but the application of two occluding balloons in the oesophagus, by using a commercially available, specially designed tube, ${ }^{17}$ was unsuccessful in our hands in preliminary experiments. The subjects had great difficulty in tolerating the pressure from the inflated balloons and a free aspiration flow could not be sustained. As Meyers and Orlando ${ }^{1}$ experienced similar difficulties, we chose to adopt the technique described by Brown et $a l^{2}$ which involves continuous perfusion of a $10 \mathrm{~cm}$ open segment of the distal oesophagus. This procedure did not result in larger contamination with salivary bicarbonate than in studies using occluded segments.

In the present investigation of nine healthy volunteers the median rates of intrinsic oesophageal bicarbonate secretion were 89 (25-150) and $121(38-284) \mu \mathrm{mol} / \mathrm{h} / 10 \mathrm{~cm}$, respectively, after pretreatment with omeprazole and ranitidine. These results are similar to previous findings by Meyers and Orlando, ${ }^{1}$ who reported a median rate of intrinsic oesophageal bicarbonate secretion in 10 healthy subjects of $156(10-472) \mu \mathrm{mol} / \mathrm{h} / 10$ $\mathrm{cm}$. Surprisingly, Brown et $a l^{2}{ }^{16}$ found median rates of $306(96-510)$ and 489 (130-1050) $\mu \mathrm{mol} / \mathrm{h} / 10 \mathrm{~cm}$, respectively, and the same low contamination by salivary and gastric bicarbonate, but these investigators achieved a much lower recovery in the perfused segment than that in the present study.

As reflux of acidic gastric contents to the distal oesophagus may neutralise the small amounts of secreted bicarbonate, suppression of gastric acid secretion is mandatory to obtain valid results of oesophageal bicarbonate secretion. In previous studies on human oesophageal bicarbonate secretion ranitidine was used for acid suppression. ${ }^{12}$ We compared the effect of omeprazole on oesophageal bicarbonate secretion with that of ranitidine, because of recent findings that omeprazole enhances bicarbonate secretion in the duodenum. ${ }^{6}$ Also the finding that high doses of ranitidine (about $2 \mathrm{~g}$ daily) are inferior to omeprazole in reducing the number of reflux episodes, despite equally significant reduction in gastric acid secretion, ${ }^{18}$ suggests that factors other than considerable and prolonged acid inhibition $^{19} 20$ may contribute to the therapeutic effect of omeprazole. Nevertheless, the results of the present study do not support the hypothesis that omeprazole and ranitidine in equipotent doses act differently on oesophageal bicarbonate secretion. The theory that omeprazole may act directly on a bicarbonate transport mechanisms seems unlikely.

In conclusion, the present study supports the concept that intrinsic oesophageal bicarbonate secretion may add to the salivary component of acid neutralisation, but the secretory capacity of the mucosa lining the oesophageal wall seems lower than previously assumed. As omeprazole and ranitidine did not affect oesophageal bicarbonate secretion differently it is unlikely that omeprazole acts on bicarbonate secretory cells.

Part of this work was presented at the Annual Meeting of the American Gastroenterological Association in San Diego in May 1995 (Gastroenterology 1995; 108: A166) and was skilful technical assistance of B Bukhave is gratefully acknowledged.

1 Meyers RE, Orlando RC. In vivo bicarbonate secretion by human esophagus. Gastroenterology 1992; 103: $1174-6$.

2 Brown CM, Snowdon CF, Slee B, Sandle LN, Rees WDW. Measurement of bicarbonate output from the intact human oesophagus. Gut 1993; 34: 872-80.

3 Helm JF, Dodds WJ, Hogan WJ, Soergel KH, Egide MS, Wood CM. Acid neutralizing capacity of human saliva. Gastroenterology 1982; 83: 69-74.

4 Helm JF, Dodds WJ, Pelc LR, Palmer DW, Hogan WJ, Teeter BC. Effect of esophageal emptying and saliva on clearance of acid from the esophagus. N Engl F Med 1984; 310: 284-8

5 Helm JF, Dodds WJ, Hogan WJ. Salivary response to esophageal acid in normal subjects and patients with reflux esophagitis. Gastroenterology 1987; 92: 1393-7.

6 Mertz-Nielsen A, Hillingsø J, Bukhave K, Rask-Madsen J. Omeprazole promotes proximal duodenal mucosal bicarbonate secretion in humans. Gut 1996; 38: 6-10.

7 Eriksson S, Langström G, Rikner L, Carlsson R, Næsdal J. Omeprazole and $\mathrm{H}_{2}$-receptor antagonists in the acute 
treatment of duodenal ulcer, gastric ulcer and reflux oesophagitis: a meta-analysis. Eur $\mathcal{f}$ Gastroenterol Hepato $1995 ; 7: 4$

8 Wilde MI, McTavish D. Omeprazole. An update of its pharmacology and therapeutic use in acid-related disorders. Drugs 1994; 48: 91-132.

9 Knutson L, Flemström G. Duodenal mucosal bicarbonate secretion in man. Stimulation by acid and inhibition by the alpha ${ }_{2}$-adrenoceptor agonist clonidine. Gut 1989; 30: $1708-15$.

10 Mertz-Nielsen A, Hillingsø J, Bukhave K, Rask-Madsen J. Indomethacin decreases gastroduodenal mucosal bicarbonate secretion in humans. Scand $\mathcal{F}$ Gastroenterol 1995; 30: 1160-5.

11 Kuo J, Fox E. Sigma Stat manual, microcomputer tools for the scientist. Revision SSD-1.0. Augsburg, Germany: Jande Scientific, 1992

12 Al Yassin TM, Toner PG. Fine structure of squamous epithelium and submucosal glands of human oesophagus. $\mathcal{f}$ Anat 1977; 123: 703-21.

13 Hamilton $\mathrm{BH}$, Orlando RC. In vivo alkaline secretion by mammalian esophagus, Gastroenterology 1989; 97: 640-8.

14 Timmer R, Breumelhof R, Nadorp JHSM, Smout AJPM. Recent advances in the pathophysiology of gastrooesophageal reflux disease. Eur $\mathcal{f}$ Gastroenterol Hepatol 1993; 5: 485-91.
15 Dent J, Dodds WJ, Friedman RH, Sekiguchi T, Hogan WJ, Arndorfer RC, Petrie DJ. Mechanism of gastroesophageal reflux in recumbent asymptomatic human subjects. $\mathcal{F}$ Clin Invest 1980; 65: 256-67.

16 Brown CM, Snowdon CF, Slee B, Sandle LN, Rees WDW. Effect of topical oesophageal acidification on human salivary and oesophageal alkali secretion. Gut 1995; 36: 649-53.

17 Sarosiek J, Hetzel DP, Yu Z, Piascik R, Li L, Rourk RM, McCallum RW. Evidence on secretion of epidermal growth factor by the esophageal mucosa in humans. $\mathrm{Am}$ growth factoronterol 1993; 88: 108-17.

18 Collen MJ, Strong RM. Comparison of omeprazole and ranitidine in treatment of refractory gastroesophageal reflux disease in patients with gastric acid hypersecretion Dig Dis Sci 1992; 37: 897-903.

19 Bate CM, Booth SN, Crowe JP, Mountford RA, Keeling $\mathrm{PW}$, Hepworth-Jones B, et al. Omeprazole $10 \mathrm{mg}$ or $20 \mathrm{mg}$ once daily in the prevention of recurrence of reflux oesophagitis. Solo investigator group. Gut 1995; 36: 492-8.

20 Hallerbäck B, Unge P, Carling L, Edwin B, Glise H, Havu N, Lyrenäs $\mathrm{E}$, Lundberg $\mathrm{K}$. Omeprazole or ranitidine in long-term treatment of reflux esophagitis. The Scandinavian Clinics for United Research Group. Gastroenterology 1994; 107: 1305-11. 